\title{
OS PROFISSIONAIS DA EDUCAÇÃO E AS SUAS RELAÇÓES COM A COMUNIDADE ESCOLAR: APRENDIZAGENS NO PROCESSO DE QUALIFICAÇÁOO DA ESCOLA MEDIADO PELA AVALIAÇÁO INSTITUCIONAL
}

\author{
Mara Regina Lemes de Sordi*
}

O diálogo entre profissionais da educação e os múltiplos atores envolvidos nas redes públicas de ensino é considerado indispensável para a qualificação da escola. Esse intercâmbio se desenvolve de modo mais concreto, quando subsidiado por evidências produzidas em processos de avaliação institucional participativo. Destaca-se que a avaliação da qualidade do projeto pedagógico da escola beneficia-se quando profissionais de educação utilizam recursos da investigação, apreendidos em seus processos de formação, como estratégias que qualificam o olhar para a realidade escolar com a devida inclusão das perspectivas complementares dos demais atores igualmente interessados no aperfeiçoamento do projeto educacional.

Palavras-chave: Avaliação institucional. Escola pública. Evidências de pesquisa. Formação de professores. Participação. Projeto pedagógico.
${ }^{*}$ Mestre em Educação - Unicamp Docente da Faculdade de Educação - Unicamp Campinas - SP [Brasil] maradesordi@uol.com.br

**Departamento de Educação Pontifícia Universidade Católica do Rio de Janeiro e Universidade Católica de Petrópolis Rio de Janeiro e Petrópolis - RJ [Brasil]

menga@puc-rio.br 


\section{Introdução}

A crescente aceitação de que a Avaliação Institucional (AI) potencializa o desenvolvimento da escola e o aprimoramento de seu projeto pedagógico (PP) tem influenciado e ampliado o campo de interesse dos profissionais da educaçáo para entender melhor as formas de implantação desse processo. A discussão sobre a inclusão de processos de AI na agenda política se mostra estratégica para que se evite cair no equívoco de entender esse movimento como o redentor de todos os problemas da escola.

A incorporação de vocábulos tidos como "mágicos" e inovadores, seguidos de processos precarizados de implantação dessa política, pode conduzir a uma simplificação perigosa dos problemas que afligem a educação básica, reforçando o descrédito das práticas de avaliação institucional.

Cabe à avaliação função mediadora para reafirmar os pressupostos de um projeto pedagógico (PP), politicamente situado e emancipatório, que se mostra exigente de um conjunto de condiçóes, capaz de sustentar os encaminhamentos que seguem a pós-avaliação.

Sempre é bom lembrar que a qualidade da educação não depende, unilateralmente, da frequência com que se "mede" a eficácia do trabalho executado pela escola, expressa na forma de êxitos dos alunos nos exames de proficiência. A avaliação só pode ser associada diretamente à qualidade, quando a instituição escolar, por meio de sua comunidade, se apropria dos dados gerados pela avaliação, interpreta-os e lhes atribui significados que interferem no processo decisório.

Subsequente a todo processo avaliativo, a tomada de decisão se impóe para evitar que a avaliação se restrinja a diagnósticos da realidade, sem nenhum compromisso com sua alteraçáo. Mudar a realidade, no entanto, sem o uso de dados confiáveis de avaliação, implica riscos de agir, de modo improvisado e intuitivo, no campo de políticas públicas socialmente relevantes como a educação. 
A avaliação institucional, ao ser tomada como instrumento para a administração da escola, requer que seu processo seja permanente, global, dialogado e plural. Nesse processo, o envolvimento da comunidade escolar não pode ser estanque e a participação não pode ficar restrita a etapas de menor expressão, tais como o preenchimento dos instrumentos de coleta.

Processos de avaliação da qualidade de uma instituição complexa como a escola são, por natureza, conflituosos. Alimentam-se, paradoxalmente, dos conflitos provenientes dos múltiplos olhares e percepçôes dos atores sobre a realidade, para formular os consensos que sustentarão as tomadas de decisão sobre a escola, devidamente referenciados ao projeto pedagógico. Pronunciarse acerca da qualidade de uma instituição apenas se concretiza quando se desenvolve de forma participativa, democrática e com transparência valorativa (ÂNGULO RASCO, I998).

Dias Sobrinho (2005) ressalta que, no paradigma qualitativo de avaliação, os sujeitos dos processos educacionais são os que têm mais autoridade intelectual e profissional para avaliar as atividades e os resultados das práticas educativas (2005, p. 29).

Parece importante demarcar que a implantação de processos de AI, seja por adesão voluntária das escolas, seja por decisão de uma rede de ensino, não implica garantia de qualidade, por simples extensão. Cumpre, entretanto, não menosprezar as possibilidades latentes desses processos como estratégia de qualificação das escolas, os quais se mostram mais eficazes, sob o ponto de vista de suas repercussóes práticas, quando assumidos como uma política de Estado. Essa condição favorece a capilaridade da proposta, ensejando compromisso e coerência com o projeto, promovendo ações e decisóes mais orgânicas tanto em nível da secretaria da educação quanto nas demais secretarias envolvidas com os fatores associados que afetam a qualidade da escola (integralidade das políticas públicas). 
Igualmente, cabe admitir que a legitimidade política do processo de avaliação é favorecida quando a decisão de se autoconhecer e se autoavaliar parte das escolas, razão pela qual essa prática é muito associada à adesão voluntária.

A questão se torna nevrálgica quando se observa que processos de AI promovidos pelas escolas, isoladamente, nem sempre conseguem priorizar tempos e espaços próprios para reflexão e avaliação, se tiverem de concorrer com as demandas sistêmicas que recaem a toda hora sobre a escola. Aprende-se muito mais sobre AI, concretizando esse processo, ainda que de forma tímida, do que teorizando sobre as vantagens a serem extraídas dessa avaliação quando se alcançarem as condiçóes ideais de aplicabilidade na escola que temos.

Idealmente, o campo da avaliação da escola deveria afastar-se da lógica que supóe que qualidade se obtém à custa de pressáo sobre os atores nela atuantes. Evidentemente que processos verticais de gestão podem tentar "impor" que a escola apresente melhoras nos indicadores de qualidade definidos. Em geral, essas pressóes até surtem algum efeito pontual, mas tendem a não se firmar ao longo do tempo, pois acabam padecendo de falta de sustentabilidade política.

$\mathrm{O}$ viés regulatório que hoje predomina nos processos de avaliação externa existentes, para diminuir os grandes efeitos colaterais que gera, precisa da autoavaliaçáo interna para estabelecer um contraponto e promover a perspectiva formativa da avaliação.

Não parece sensato desqualificar, a priori, processos de AI engendrados de "cima para baixo", sem que se examinem radicalmente as premissas que orientam o formato avaliativo proposto e quanto ele se alicerça nos princípios da participação dos atores da escola, reconhecendo-os como protagonistas que dialogam com outros atores, igualmente protagônicos em suas esferas próprias de governabilidade. Isso inclui os gestores centrais do serviço público que devem administrar e regular a instituição de ensino, tendo como foco o aluno e seu direito de aprender, o que abrange a equipe diretiva da escola que pode evidenciar seu compromisso social na forma como dinamiza a vida dos atores em prol de um projeto pedagógico que garanta os direitos das crianças 
de aprender e em consonância com as exigências legais e as diretrizes do sistema a que se vincula e representa. Some-se a isso o protagonismo do professor, responsável direto pela concretude das políticas públicas, por meio da gestáo das aprendizagens de seus alunos em sala de aula e corresponsável pela gestâo do PP do estabelecimento escolar.

Processos de avaliação institucional participativa (AIP) ajudam a recuperar a visão de totalidade da instituição tanto nos processos e dimensôes avaliados quanto no que se refere aos atores envolvidos e à sua participaçáo quantitativa e qualitativa da vida institucional.

Ao resgatar o interesse da comunidade pelo processo de construçáo da qualidade de ensino, a AIP aciona os diferentes atores da escola para que assumam responsabilidades na corregulação do processo. Participar de um processo de AIP estimula o exercício da observaçâo formativa da escola, possibilitando a análise de seu contexto e de suas relaçóes com o entorno social; implica a aprendizagem da escuta sensível dos outros sujeitos e desenvolve, nos atores, a capacidade para negociar perspectivas e fortalecer alianças. Enfim, a AIP redistribui poder entre os atores chamados a participar, "mexe" com o instituído e, consequentemente, altera os processos de trabalho da escola.

As regulaçóes nacionais (sistêmicas), distantes do raio de ação da escola, não têm conseguido mobilizar os atores situados na periferia do sistema, fazendo-os envolver-se com o espírito das reformas. Fragilizadas em sua legitimidade política, acabam servindo mais de banco de informaçóes sobre a escola, rapidamente desprezado. A AIP, por meio das microrregulaçóes locais que promove e estimula, em especial quando ocorrem de modo organizado, supera, com larga vantagem, os processos de regulaçáo nacional (centro do sistema), de acordo com Barroso (2005). Em especial, porque a noção de pertencimento diminui as resistências que comumente ocorrem quando a comunidade náo se sente valorizada e incorporada no processo. Mobiliza os atores a querer pronunciar-se no processo e a cuidar do projeto. 
Um campo que, em geral, ocasiona tensão entre os atores envolvidos nos processos de AIP refere-se à identificação dos problemas da escola e à eleição daqueles que merecem prioridade nos planos de ação. Em decorrência disso, o equacionamento das diferenças de perspectiva de análise sobre esse fenômeno pode trazer de volta o risco da reprodução das hierarquias, dos saberes e dos poderes comumente presentes na cultura escolar. A AIP pode servir para que se explicitem a disputa de poder no âmbito do projeto da escola e suas possibilidades redistributivas.

\section{A redistribuição de poder na seleção dos indicadores de qualidade da escola}

Um dos momentos mais importantes para o processo de AIP se concentra na definição dos indicadores de qualidade das escolas que servem de norte para a avaliação, pois ancoram o diagnóstico da realidade, momento primeiro e de cunho localizador da situação atual da escola, além de informarem sua relação de proximidade/distância, em confronto com a imagem de futuro sinalizada no PP. Disso deriva a seleção e priorização dos problemas que serão enfrentados para que a escola se movimente na direção pretendida.

Supóe-se que a prática de avaliaçáo da qualidade da e na escola constitui campo de familiaridade para os profissionais que nela atuam, posto que, cotidianamente, são instigados a emitir juízos de valor sobre o processo educacional, subsidiando, em maior ou menor grau, as tomadas de decisão. Tratase de examinar um cenário conhecido, informalmente criticado, legitimado pelo reconhecimento da expertise tantas vezes atribuída aos profissionais da educação. Dificuldades na explicitação dos indicadores de qualidade estariam mais concentradas nos atores não profissionais, e isso implicaria cuidado da equipe para não desconsiderar a percepção desses segmentos menos organizados, impondo-lhes uma visão de escola marcada pelo ethos profissional. 
Parece, entretanto, que os profissionais da educação sabem dizer que qualidade querem construir, mas não necessariamente como ela se manifesta na forma de indicadores. Sabem dizer quais problemas a escola enfrenta, mas demonstram dificuldades em apresentar evidências daquilo que afirmam. Querem melhorias e soluçóes concretas, mas tendem a não saber construir uma rede explicativa desses problemas, o que prejudica a seleção das estratégias de superação e os encaminhamentos mais potentes.

Isso nos levou a indagar como esses profissionais têm sido introduzidos no debate sobre a eficácia da escola, de modo que possam compreender as lógicas presentes e como funcionam os vetores que afetam esse campo de forças, auxiliando-os a tomar posição a favor da eficácia social da escola.

A compreensão da escola como totalidade a ser desvendada e as razóes pelas quais sua avaliação tem tido tanta centralidade nas políticas educacionais parecem ser componentes essenciais da formação de professores, gerando base ético-política e técnico-científica que os instrumentaliza a avaliar a qualidade da escola. É por isso que sua formação merece ser examinada, de maneira que possam construir e consolidar processos de qualificaçáo da escola, realizando-os, de modo colaborativo, com os demais atores sociais.

\section{O diálogo entre evidências empíricas e teóricas no processo de formação de professores e a qualificação da escola}

A incorporação da pesquisa como componente estratégico da formação de professores, exerce importante contribuição na qualidade da intervenção do docente na realidade da escola, tornando-o potencialmente mais capaz de observar, descrever, compilar evidências, analisar e interpretar os fenômenos educativos para além de sua aparência. Hargreaves (2007) estabelece crítica sobre a forma como esse eixo vem sendo ensinado, pois parece náo se in- 
corporar como valor, tendendo a desaparecer do discurso e das práticas dos professores, tão logo entram no mundo do trabalho e se inserem na escola.

Observa-se que não basta avaliar a escola que temos sem recuperar o debate sobre a escola que precisamos construir.

Broadfoot (2007) destaca os significados de algumas opçóes nos processos de avaliação da qualidade de alguns cursos:

[...] even value-added measures still constrain the focus of quality to the criteria laid down for measurement and cannot embrace some of the more intangible, but perhaps most important, aspects of a school's ethos. These might include giving students a love of learning and the skills to become lifelong learners, or producing students who are likely to become worthwhile and caring future members of society. (BROADFOOT, 2007, p. 66).

A diversidade de ênfases, que podem ser dadas quando o debate versa sobre qualidade de um projeto educacional, torna o processo de avaliaçáo fluido e delicado. Pode ser considerado bom um projeto que se isenta da responsabilidade de uma formação com pertinência social? Pode-se considerar eficaz um projeto educativo que se norteia apenas pelos resultados dos alunos nos exames de proficiência? Pode ser boa uma escola em que as crianças são aprovadas sem que aprendam?

A pesquisa, tomada como um ingrediente básico das competências desejadas do profissional da educação, ao ser incorporada nos cursos de formação, tende a ampliar a visão do professor diante da realidade da escola e o ajuda a ordenar seu processo de trabalho. Agregado como valor da formação, esse olhar epistemologicamente curioso potencializa, em cada professor, a condição de pronunciar-se sobre o trabalho escolar, indicando aquilo que se tem mostrado eficaz para produzir aprendizagens e formas de superar os limites da realidade. 
Professores familiarizados com o eixo da investigação mostram-se mais atentos às lógicas das políticas públicas de educação, à realidade de seus alunos e de seus pares e aos dados da avaliação. Tendem a certo inconformismo que os estimula a formular perguntas e a contestar a realidade quando esta não lhes faz sentido.

Muitos conhecimentos, derivados do exercício prático do professor, podem ser perdidos se ele não souber sistematizar as evidências das boas práticas pedagógicas que produz nem socializá-las. Isso se estende aos saberes que a comunidade escolar igualmente possui sobre a escola e que podem ser descartados pelas mesmas razóes, reduzindo a potência dos diálogos entre distintos saberes que não circulam em relaçôes intersubjetivas fechadas a aprendizagens colaborativas e fortemente hierarquizadas.

Essa interrupção das conexões possíveis e desejáveis entre as diferentes formas de conhecer uma determinada realidade fragiliza os pactos de qualidade com os atores sociais envolvidos, favorecendo descontinuidades e descompromissos. Isso causa uma sensação de eterno recomeço, pessoal e institucional, e despotencializa a ação transformadora da realidade da escola.

Arriscamo-nos a dizer que há um enorme vazio entre as investigaçóes sobre a escola e quanto elas ajudam a mudar a realidade educacional. Muitos saberes que poderiam afetar a eficácia social da escola são desprezados em razão da sua ausência nos processos de avaliação externa, revelando os referenciais de qualidade que se quer impor.

[...] a qualidade das atividades desenvolvidas pela escola (em qualquer nível) não pode ser valorizada apenas por sua instrumentalidade como veículo para produzir benefícios extrínsecos à educação [...] Devem reger-se pelo compromisso de ampliação de perspectiva cognitiva dos envolvidos com transformaçôes qualitativas em sua visão geral da vida e do mundo (ELLIOTT, 2007, p. I86-I87). 
Uma formação humana que amplie a capacidade cognitiva das pessoas, que as auxilie a ler e interpretar o mundo em que vivem e a decidir as formas de inserção social que querem ter, em nossa perspectiva, revela indicadores potentes de qualidade de uma instituição educativa, ainda que suas repercussôes não sejam muito mensuráveis nem sequer visíveis em curto prazo. É provável que nem sejam questóes levadas em conta nos exames de desempenho de alunos. Deveriam, por esse motivo, ser banidas dos projetos pedagógicos?

Projetos de AI emprestam grande contribuição ao PP pela possibilidade de reinstituírem a necessidade do estar junto e do pensar coletivo. $\mathrm{O}$ encontro dos múltiplos atores ajuda a reunir e circular os saberes necessários para enfrentar os problemas da realidade, ampliando a legitimidade técnica e política do processo.

Em geral, a comunidade escolar tem pequeno repertório de participaçóes na vida da escola, especialmente quando a discussão se refere às funçóes finalísticas dessa instituição. Desprovidos dessa experiência, os segmentos tendem a não tomar para si, como direito, as decisóes que mais diretamente afetam a concepção de qualidade da escola. E, dessa forma, tendem a se encontrar desarmados para o trabalho de avaliação dessa qualidade. Não se duvida, no entanto, de que sejam capazes de avaliar. O que está em discussão é a necessidade de conhecer os indicadores que usam, formal ou informalmente, para proceder a seus juízos de valor sobre o que veem na realidade da escola e, posteriormente, cotejá-los com outros produzidos pelos atores profissionais da escola, buscando formular um pacto de qualidade, negociado de forma transparente e que oriente os processos de avaliação da qualidade. (BONDIOLI, 2004).

A realidade da escola náo se deixa capturar facilmente, menos ainda em momentos pontuais de medição por meio de instrumentos fechados ou limitados a perspectivas monorreferenciais. Em razão dessa dificuldade, mais do que nunca, a aprendizagem da investigação se revela precioso recurso para o processo de trabalho docente, inclusive para conceber formatos avaliativos amplos que associem e saibam fazer dialogar abordagens quantitativas e qua- 
litativas da escola, ajudem a buscar a essência dos problemas e subsidiem o trabalho de tradução de seus significados com o coletivo de atores da escola.

Dessa aliança com os atores da escola depende seu processo de qualificação. Muito há que avançar para que profissionais da educação se acostumem a ouvir o que falam os demais atores a respeito da escola que querem ajudar a construir. Muito há de se desenvolver para que essa interlocução seja frutífera e ambos os segmentos habituem-se a sustentar seus argumentos, trazendo evidências concretas do que falam, do que pensam, do que viram e por que entendem ser relevante para a produçáo do bem coletivo.

Segundo Thomas (2007), evidência é informação que sustenta (ou refuta) uma afirmação e deve passar pelo teste da relevância, da suficiência e da veracidade, se quiser ter credibilidade. Para ajudar no exame de sua relevância, deve ser analisada com outras informaçóes para determinar seu lugar na sustentação da afirmação (teste de suficiência). A qualidade e a suficiência das evidências estâo relacionadas com as ambiçóes epistemológicas da proposição.

Outro aspecto importante que deve ser considerado refere-se ao teste da veracidade das evidências, o qual pretende avaliar se são dignas de confiança ou se estão comprometidas pelos interesses de quem as formulou, servindo à manipulaçáo e ou à distorçáo dos fatos.

Merece destaque, portanto, o contexto social e interpretativo das evidências, pois como todo processo social, a avaliação envolve juízos de valor permeados pela credibilidade dos atores sociais que participam do processo.

Sabe-se que ainda são recentes as experiências de participação autêntica dos diversos atores sociais nos processos de qualificaçấo da escola. Isso nos reporta ao exame da cultura de alguns profissionais da educação. Até que ponto aceitam que famílias, estudantes, funcionários têm saberes próprios e significativos que ajudam a construir uma escola de qualidade? Como encaram as evidências trazidas por esses segmentos que tentam expressar as áreas de excelência da escola e os pontos de fragilidade sob sua ótica particular? Estáo autorizados a se pronunciar sobre a qualidade da escola ou esta requer 
conhecimentos mais elaborados que, em geral, se circunscrevem à sua equipe de profissionais?

Esse raciocínio se torna igualmente polêmico quando se desqualificam os saberes dos professores em relação aos científicos derivados das pesquisas produzidas pelos docentes das universidades.

$\mathrm{O}$ advento da educação, com base em evidências como possibilidade de qualificação das práticas pedagógicas desenvolvidas nas escolas, pode potencializar os processos de AI, na medida em que aceitamos que todos nós usamos "atos interpretativos comuns" de forma que nos ajudem a ordenar e compreender o mundo (HARGREAVES, 2007).

Logo, parece fazer sentido aprender a olhar com inteligência e perspicácia a realidade que nos cerca, buscando reunir evidências do que parece ser adequado ou inadequado ao êxito do projeto da escola. Tomadas como ponto de partida para a análise da situação e devidamente analisadas quanto à relevância, suficiência e veracidade do que informam, podem-se mostrar bastante fecundas para instigar o debate entre sujeitos sociais diferentemente alocados na escola, mas igualmente interessados em que ela tenha qualidade.

Hargreaves (2007) destaca, no entanto, que os professores têm tido pouco êxito no emprego das evidências de pesquisa com o conhecimento prático de que dispóem. Dessa forma, as evidências nascidas da prática não avançam na direção de evidências corroborativas, pois não exploram nem são cotejadas com as que se baseiam na pesquisa educacional.

Acreditamos que a avaliação da escola, como instituição complexa e plural, pode beneficiar-se da aproximação entre saberes científicos e práticos, contrabalançando a prática baseada em evidências com as que se baseiam também em prática e em pesquisa.

A aprendizagem da pesquisa da realidade escolar e a investigação científica sobre a escola podem-se potencializar mutuamente. O que exige reflexão, no entanto, é se os dados de pesquisa são disponibilizados para contribuir com o conjunto de evidências trazidas pelo professor e/ou pelos demais atores 
da escola, ou são vistos como um meio de impor o que é supostamente "eficaz", silenciando saberes e reproduzindo hierarquias.

Para a avaliação institucional, a resposta a essa provocação faz toda a diferença no pacto de qualidade que se quer firmar. Afinal, não há como bem avaliar sem entender que um avaliador, qualquer que seja ele, simultaneamente, precisa desenvolver-se como pesquisador da realidade, como colecionador de evidências bem sustentadas, como comunicador e produtor de sentidos, como mediador de conflitos, negociador de prioridades e formulador de encaminhamentos.

Microdecisōes pedagógicas que privilegiem a inserção precoce dos estudantes dos cursos de formação de professores em situações de trabalho desenvolvidas pelos profissionais das escolas dáo concretude ao trabalho de investigação da realidade escolar. Isso contribui para que aprendam a encontrar evidências anunciadoras da presença ou ausência da qualidade social da escola em sua função fim: a promoção da aprendizagem nas crianças. Tornam visível a coerência das práticas em relação ao discurso do projeto pedagógico da instituição. Contribuem para resgatar o interesse dos estudantes pelo estudo da escola, além de aumentar as chances de gerar compromisso com seu processo de qualificação. "If students are 'careless', 'lazy', 'easily distracted', or 'lack interest this is a symptom of lack of engagement, rather than an explanation per se". (BROADFOOT, 2007, p. II6).

Exercitada desde cedo nas dinâmicas curriculares dos cursos de formação de professores, a opção metodológica que envolve a investigação desenvolve a acuidade dos futuros profissionais para a coleta de evidências empíricas que informem a coerência ético-epistemológica do trabalho pedagógico com os valores presentes no discurso do projeto. O contato com a realidade escolar, mediado inicialmente pelo diálogo com os profissionais da educação e, complementarmente, com a comunidade interna e externa da escola, ensinará a aprender que evidências da qualidade de uma escola não podem ser buscadas apenas na perspectiva da eficácia instrumental. Ensinará ainda que qualidade 
é um conceito abstrato e reclama por explicitação de suas bases, exigindo, portanto, a definição de seus indicadores de presença e de êxito, pois,

[...] no contexto da pesquisa direcionada ao aprimoramento da prática educativa, os professores devem ser envolvidos na priorização dos seus objetivos educativos em uma dada situação, na definição do que deve contar como evidências relevantes do grau no qual estão sendo realizados e na interpretação da importância prática para eles. Em outras palavras, a pesquisa educacional, ao contrário da simples pesquisa sobre educação, deve envolver os professores em sua construção e execução e não simplesmente na aplicação de suas conclusôes. (ELLIOTT, 2007 p. 190).

A aprendizagem da avaliação institucional, com sua natureza multifacetada, plural e complexa, ocorrerá pela agregação de sentidos pedagógicos e políticos à formação. A possibilidade de uma relação formativa com a avaliaçáo, dialogada e compartilhada, de modo transparente, contribui para que esses profissionais se familiarizem com esse processo, levando-os a aprender e a ensinar a extrair da avaliaçáo os subsídios indispensáveis para o monitoramento da pertinência social dos objetivos assinalados no projeto pedagógico da escola.

A avaliação se constitui como prática social, pois envolve

[...] forma coerente e complexa de atividade humana cooperativa, estabelecida socialmente, através da qual benefícios internos àquela forma de atividade acontecem ao se tentar atingir esses padróes de excelência que são adequados e parcialmente definidores daquela forma de atividade, com o resultado de que os poderes humanos para atingir excelência e as concepçôes humanas dos fins e benefícios são sistematicamente ampliados. [...] Investiga-se a realidade da escola 
para promover um processo educativo coerente em determinados contextos práticos e não para descobrir conexôes contingentes entre um conjunto de atividades de sala de aula e resultados de aprendizagem padronizados de antemão. ( ELLIOTT, 2007, p. I84-I89).

Pela natureza do processo de AI, o espírito investigativo dos diferentes sujeitos/avaliadores parece ser estratégica e geradora de boas práticas pedagógicas nas escolas. Tais práticas, devidamente contextualizadas e atualizadas, poderão contribuir para que a construção social do conhecimento sobre os processos de qualificação das escolas possa ser compartilhada solidariamente, acelerando as possibilidades de as crianças da escola pública terem, finalmente ampliadas, suas chances de acesso ao conhecimento historicamente acumulado.

\section{Os profissionais da educação e o "uso de si" no envolvimento da comunidade escolar na avaliação institucional}

Se temos consenso sobre a importância da participação democrática na vida da escola dos diferentes segmentos, a questão se torna nevrálgica quando pensamos em participação igualmente democrática na avaliação institucional. A quem compete articular o grupo de atores para que caminhe, com alguma segurança, num processo cujas bases desconhece, fortemente influenciado pelos interesses economicistas, veiculados pela mídia, que parecem validar uma certa concepção de qualidade e avaliação utilitarista e desprovida de pertinência social?

Defendemos que a articulação do processo de AIP compete aos profissionais da escola, cabendo-lhes a orquestração das forças presentes. As mediaçóes esperadas desses atores, que desfrutam socialmente de legitimidade 
técnica para o uso da voz na condução de processos avaliatórios na escola, exigem um planejamento meticuloso das estratégias e táticas que se mostram mais potentes naquela cultura.

O papel político desenvolvido pelos profissionais nesse campo implica disposição para o "uso de si", dada a cultura de resistência à avaliação que domina os cenários escolares e que certamente se inscreve, de uma forma ou outra, nas maneiras de participação da comunidade, mesmo que diferentemente matizadas.

O contexto atual das políticas na educação, dado que prioriza formas de avaliação que medem a capacidade de desempenho, pode dar sustentação a uma visão utilitarista de qualidade. Em outras palavras, é um contexto em que as práticas são tratadas como dispositivos de manipulação (tecnologias) para gerar níveis de produção desejados (ELLIOTT, 2007).

Parece ser indiscutível que os profissionais da educação, por dever de ofício, exerceráo com mais propriedade a articulação dos atores da escola. No entanto, ao fazer essa articulação, convém que não se comportem como especialistas que usam o diálogo como artifício de cooptação, sem nenhum esforço de entendimento e compromisso com a incorporação dos argumentos trazidos pelos segmentos tidos como coadjuvantes na definiçãa da concepção de qualidade que a escola precisa possuir.

Formas peculiares de ver e pronunciar-se sobre o cotidiano trazem enorme riqueza ao trabalho de qualificação da escola e são favorecidas pelo clima institucional existente que pode estimular a liberdade de expressão de opinióes. A participação em processos dialógicos de avaliação envolve a abertura dos sujeitos implicados para novas aprendizagens acerca da escola que conhecem, sob uma ótica particular.

Assim, ao movimento de descrição do observado, que comporta e requer pluralidades de visão, outros movimentos se seguem para que essas impressões, parcialmente socializadas, possam ser mais bem entendidas, a partir da compilação e explicitação das evidências que sustentam as informaçóes 
trazidas. Devidamente problematizadas no e pelo grupo de atores interessados, elas são submetidas a processos de triangulação que, pari passu, ajudam a dar maior precisão à definição dos problemas da escola. $\mathrm{O}$ cotejamento da coerência e relevância desses dados demanda cuidado para não desconsiderar as contribuiçóes dos segmentos e, simultaneamente, avançar no processo de eleição de prioridades para orientar a tomada de decisão.

Uma questão que ganha destaque é entender como os profissionais da escola exercitam sua competência coletiva, incentivando diálogos e problematizando-os. Como partícipe do coletivo, deve valer-se, igualmente, dos princípios citados por Leite, que embasam a possibilidade de todas as pessoas exercerem funçôes de governo, pelo menos por algum tempo, nas açôes avaliativas, exercitando "[...] isonomia, isegoria e isocracia, ou seja, igualdade de direitos, igualdade e franqueza no falar e igualdade no poder." ( LEITE, 2005, p. I Io).

A mediação de um grupo em processo de autoavaliação demanda alguma acuidade do articulador para a questão das evidências que sustentam as falas. Esse exercício pode revelar-se altamente formativo ao grupo como um todo, pois auxilia e evita desgastes que comprometem as relaçôes intersubjetivas do grupo, na medida em que seus integrantes transferem o debate para o campo das ideias que devem sustentar-se concretamente na força dos argumentos apresentados, e não no argumento da força e do poder.

\section{Consideraçóes finais}

Profissionais da educação podem constituir força mobilizadora dos diferentes atores sociais implicados com o projeto pedagógico da escola. Ao assumirem trabalho de articulação dessas forças em prol de um projeto de avaliação de cunho contrarregulatório, esses profissionais se póem, efetivamente, a serviço de um projeto educativo socialmente pertinente. Processos 
de formação inicial e continuada não podem furtar-se ao compromisso de incluir, em suas agendas, a discussão da AI.

A luta por uma escola que cumpra, com dignidade, sua função social que, minimamente, envolve ajudar as crianças a aprender, para além dos conteúdos, os valores democráticos de uma sociedade que precisa transformar-se, exige que os atores que nela atuam não se esquivem do "uso de si" em prol desse projeto, e um desses espaços de luta é o da avaliaçáo institucional participativa. Se não por outro motivo, pelo simples fato de essa avaliação induzir o reencontro dos sujeitos implicados com a qualificaçáo da escola, devolvendolhes protagonismo na cena, o que reacende a esperança no futuro da educaçáo que se engendra de modo solidário, organizado e intencional.

\section{EDUCATORS AND THEIR RELATIONSHIPS WITH THE SCHOOL COMMUNITY: LEARNING IN THE PROCESS OF QUALIFICATION OF THE SCHOOL THROUGH THE INSTITUTIONAL EVALUATION}

The dialogue between the professionals of education and the multiple actors involved in the public teaching network is presented as indispensable for the qualification of the school, and it is developed in a more concrete way when subsidized by evidences produced in processes of institutional participatory evaluation. It is emphasized that the evaluation of the quality of the school pedagogical project is benefited when professionals of education utilize resources of the investigation, learned during their process of formation, as strategies that qualify the perception of the school reality with the appropriate inclusion of the complementary perspectives of the various actors equally interested in the improvement of the educational project.

KEY wORDs: Evidences of research. Institutional evaluation. Participation. Pedagogical project. Public school. Teacher's training. 


\section{Referências}

ÂNGULO RASCO, J. F. Ningun paso adelante: dos pasos atrás la desaparición de la evaluación institucional Revista de Educação da PUC-Campinas, v.I, n.4, p.15-23, jun. 1998.

BARROSO, J. Politicas educativas e organização escolar. Lisboa: 2005.

BONDIOLI, A. O projeto pedagógico da creche e sua avaliação. Campinas: Autores Associados, 2004 .

BROADFOOT, P. The quality agenda. In: BROADFOOT, P. An introduction to assessment. New York: Continuum International Publishing Group, 2007. p. 63- 78.

The emerging evidence In: BROADFOOT, P. An introduction to assessment. New York: Continuum International Publishing Group , 2007. p. I09-I28.

DIAS SOBRINHO, J. Avaliação como instrumento da formação cidadã e desenvolvimento da sociedade democrática: por uma ético-epistemologia da avaliação. In: RISTOFF, D.; ALMEIDA JUNIOR, V. P. Avaliação participativa, perspectivas e desafios. Brasília, DF: INEP, 2005.

ELLIOTT, J. Tornando educativa a prática baseada em evidências. In: THOMAS, G.; PRING, R. e col. Educação baseada em evidências. A utilizaçâo dos achados científicos para a qualificação da prática pedagógica. Porto Alegre: Artmed, 2007. p.I77-20I.

HARGREAVES, D. H. Teaching as a research-based profession: possibilities and prospects. In: HAMMERSLEY, M. Educational research and evidence-based practice. London: Sage, 2007.

LEITE, D. B. C. Reformas universitárias: avaliação institucional participativa. Petrópolis, RJ: Vozes, 2005.

THOMAS, G. Introdução: evidências e prática. In: THOMAS, G.; PRING, R. e col. Educação baseada em evidências. A utilização dos achados científicos para a qualificação da prática pedagógica. Porto Alegre: Artmed, 2007. p. 9-3I.

Recebido em 7 abr. 2009 / aprovado em Io maio 2009.

\section{Para referenciar este texto}

SORDI, M. R. L. de S.; LÜDKE, M. de. Os profissionais da educação e as suas relaçóes com a comunidade escolar: aprendizagens no processo de qualificação da escola mediado pela avaliação institucional. EccoS, São Paulo, v. II, n. I, p. 209-227, jan./jun. 2009. 
